\title{
Primary disease sites and patterns of spread in cases of neurolymphomatosis in the orbit associated with lymphoma
}

\author{
Seth J. Fritzhand', Bita Esmaeli ${ }^{2}$, Jia Sun ${ }^{3}$ and J. Matthew Debnam ${ }^{4^{*}}$ (D)
}

\begin{abstract}
Background: Neurolymphomatosis involving the cranial nerves (CNs) is rare. We sought a better understanding of the primary disease sites and patterns of spread in neurolymphomatosis of the orbit and retro-orbital cranial nerves.

Methods: Patients with lymphoma and MRI evidence of neurolymphomatosis of CN II, III, IV, $V_{1}$, or $V_{2}$ were retrospectively reviewed. Demographics and primary disease site and sites of neurolymphomatosis on MRI were recorded. Wilcoxon rank sum test was used to compare number of sites of neurolymphomatosis with lymphoma type and survival.
\end{abstract}

Results: The study included 18 patients. The most frequent types of lymphoma were diffuse large B-cell (DLBCL) $(n=9)$ and marginal zone $(n=3)$. In 9 patients, lymphoma presented as a mass $(n=7)$ or infiltrative disease $(n=2)$ directly involving the orbit; in 6, a maxillofacial mass spread directly to CNs; and in 3, lymphoma at remote sites spread to orbital CNs. Overall, 81 sites of neurolymphomatosis were noted. The most common sites were the maxillary nerve $\left(V_{2}\right)$ including at the infraorbital fissure or foramen rotundum (17 patients; 19 nerves),

pterygopalatine fossa (16 patients; 19 nerves), and cavernous sinus (9 patients; 12 nerves). Number of sites of neurolymphomatosis was significantly lower for DLBCL than for other lymphoma types $(p=0.007)$. Number of sites of neurolymphomatosis did not affect survival $(p=0.26)$. The mean interval between the pathologic diagnosis and MRI documentation of the full extent of neurolymphomatosis was 39 days after pathologic diagnosis.

Conclusions: Based on our study results, neurolymphomatosis in the orbit appears to be frequently associated with an orbital and/or maxillofacial mass and commonly involves $C N V_{2}$, the pterygopalatine fossa, and the cavernous sinus. DLBCL may be associated with fewer sites of neurolymphomatosis than other lymphomas. In patients with lymphoma, a systematic search for neurolymphomatosis is imperative for early detection.

Keywords: Neurolymphomatosis, Lymphoma, Cranial nerves, Orbits

\section{Background}

Non-Hodgkin Lymphomas (NHLs) are a class of lymphoproliferative malignancies that may arise in extranodal locations and often involve both nodal and extranodal sites [1]. New treatments for NHL are leading to

\footnotetext{
* Correspondence: matthew.debnam@mdanderson.org

${ }^{4}$ Department of Neuroradiology, The University of Texas MD Anderson Cancer Center, 1400 Pressler Blvd., Unit 1482, Houston, TX 77030, USA

Full list of author information is available at the end of the article
}

longer survival times and lower mortality, and this may increase the incidence of central nervous system disease involvement. Thus, the number of patients presenting with ophthalmologic sequelae of NHL may increase [2].

Different types of malignancies can directly involve the cranial nerves which is termed perineural spread (PNS). When specific to hematological malignancies, including lymphoma, this spread along the cranial and peripheral nerves is termed neurolymphomatosis, which is rare. 
PNS and neurolymphomatosis are different from leptomeningeal disease (LMD) which is the spread of a malignancy to the cerebrospinal fluid with involvement of the leptomeninges including the arachnoid, subarachnoid space, and pia mater, and also includes the cranial nerves. Neurolymphomatosis affects patients with NHL and lack of detection may lead to a delay in diagnosis [3, 4]. The incidence of neurolymphomatosis is increasing worldwide, and this may be due to increased awareness and earlier detection with more sophisticated diagnostic techniques [5].

To the best of our knowledge, there are no large case series and only a few reports in the literature about neurolymphomatosis occurring in patients with lymphoma in or near the orbit $[2,6-8]$. To improve understanding of neurolymphomatosis in the orbit and retro-orbital cranial nerves associated with NHL, we reviewed the demographics and MR imaging findings of patients with this presentation who were treated at our institution, a major cancer center.

\section{Methods}

This retrospective study was approved by the Institutional Review Board at The University of Texas MD Anderson Cancer Center. The research was HIPAA compliant and adhered to the ethical principles in the Declaration of Helsinki as amended in 2013. Our radiological database was searched to identify patients, both children and adults, who received a pathologic diagnosis of lymphoma at our institution between August 2005 and June 2019 and had magnetic resonance imaging (MRI) evidence of neurolymphomatosis involving the CNs closest to the orbit, specifically CN II, III, IV, $\mathrm{V}_{1}$, or $\mathrm{V}_{2}$. A total of 18 patients were identified who met these criteria, and these patients were included in the study.

A head and neck radiologist (JMD) with over 20 years of experience reviewed each of the MRI studies for evidence of neurolymphomatosis, determined the extent of disease, and recorded the presence of any enhancement representing $\mathrm{NL}$ in $\mathrm{CN}$ II through CN XII, the pterygopalatine fossa (PPF), the vidian canal, and Meckel's cave. Neurolymphomatosis involving the superior orbital fissure was included as part of $\mathrm{CN} \mathrm{V}_{1}$, and neurolymphomatosis involving the infraorbital fissure or foramen rotundum was classified together with neurolymphomatosis involving $\mathrm{CN} \mathrm{V}_{2}$. The reviewed MR images of the orbits included axial T1 pre-contrast without fat saturation, orthogonal T1 post-contrast with fat saturation and axial T2 with fat saturation.

Data about survival were also obtained. The Wilcoxon rank sum test was used to correlate the number of sites of neurolymphomatosis with disease type and survival.

\section{Results}

The 18 patients in the study ranged in age from 24 to 78 years (mean, median [SD] 61, 63 [13] years) (Table 1). Lymphoma was diagnosed by biopsy in 17 patients and by lumbar puncture in 1 . The type of lymphoma was DLBCL in 9 patients, marginal zone lymphoma in 3, other forms of low-grade B-cell lymphoma in 2, mantle cell lymphoma in 2, NK/T-cell lymphoma in 1, and chronic lymphocytic leukemia/small lymphocytic lymphoma in 1 patient. MRI documentation of neurolymphomatosis preceded pathologic diagnosis of neurolymphomatosis (by up to 59 days) in 5 patients and followed pathologic diagnosis of neurolymphomatosis (by up to 176 days) in 13 patients; the mean interval (SD) between the pathologic diagnosis and MRI documentation was 39 (62) days after pathologic diagnosis. In 8 patients the lymphoma was recurrent; in these patients, the interval between initial diagnosis and diagnosis of recurrence ranged from 6 months to 11 years (mean [SD], 4.6 [4.7] years).

\section{Primary disease sites and sites of neurolymphomatosis} In 9 patients, lymphoma directly involved the orbit in the form of a mass $(n=7)$ (Fig. 1) or infiltrative disease $(n=2)$ (Table 2). In 6 patients, a maxillofacial mass spread directly to $\mathrm{CN} \mathrm{V}_{1}(n=1), \mathrm{CN} \mathrm{V}_{2}(n=4)$, or the PPF $(n=1)$ (Fig. 2). In 3 patients, distant disease spread to $\mathrm{CNs}$ in the orbital or periorbital area was characterized by $\mathrm{CN}$ thickening and enhancement, and there was no orbit or maxillofacial mass (Fig. 3).

Overall, 81 sites of neurolymphomatosis were localized on MRI. The most common sites of neurolymphomatosis were $\mathrm{V}_{2}$ including at the infraorbital fissure or foramen rotundum (17 patients; 19 nerves), the PPF (16 patients; 19 nerves), and the cavernous sinus (9 patients; 12 nerves). CN II was involved in 4 cases and in all 4 of these cases there was also neurolymphomatosis on V2. In patient \#18 there was spread of disease to involve $\mathrm{CN}$ VII. There was no involvement of CN I, CN III, CN IV, $\mathrm{CN}$ VI, or CN VIII through CN XII.

The 9 cases of DLBCL were associated with 26 sites of neurolymphomatosis, while the 9 cases of other types of lymphoma were associated with 55 sites of neurolymphomatosis. The number of sites of neurolymphomatosis was significantly lower for DLBCL than for the other types of lymphoma $(p=0.007)$. The appearance of disease in the orbits and sites of neurolymphomatosis by tumor type are described in Table 2.

\section{Treatment and follow-up}

Sixteen patients were treated with chemotherapy and 2 with radiation (Table 1). Six of the 18 patients (33\%) died during follow-up. Five of these patients had DLBCL, and 1 had low-grade B-cell lymphoma. No correlation 


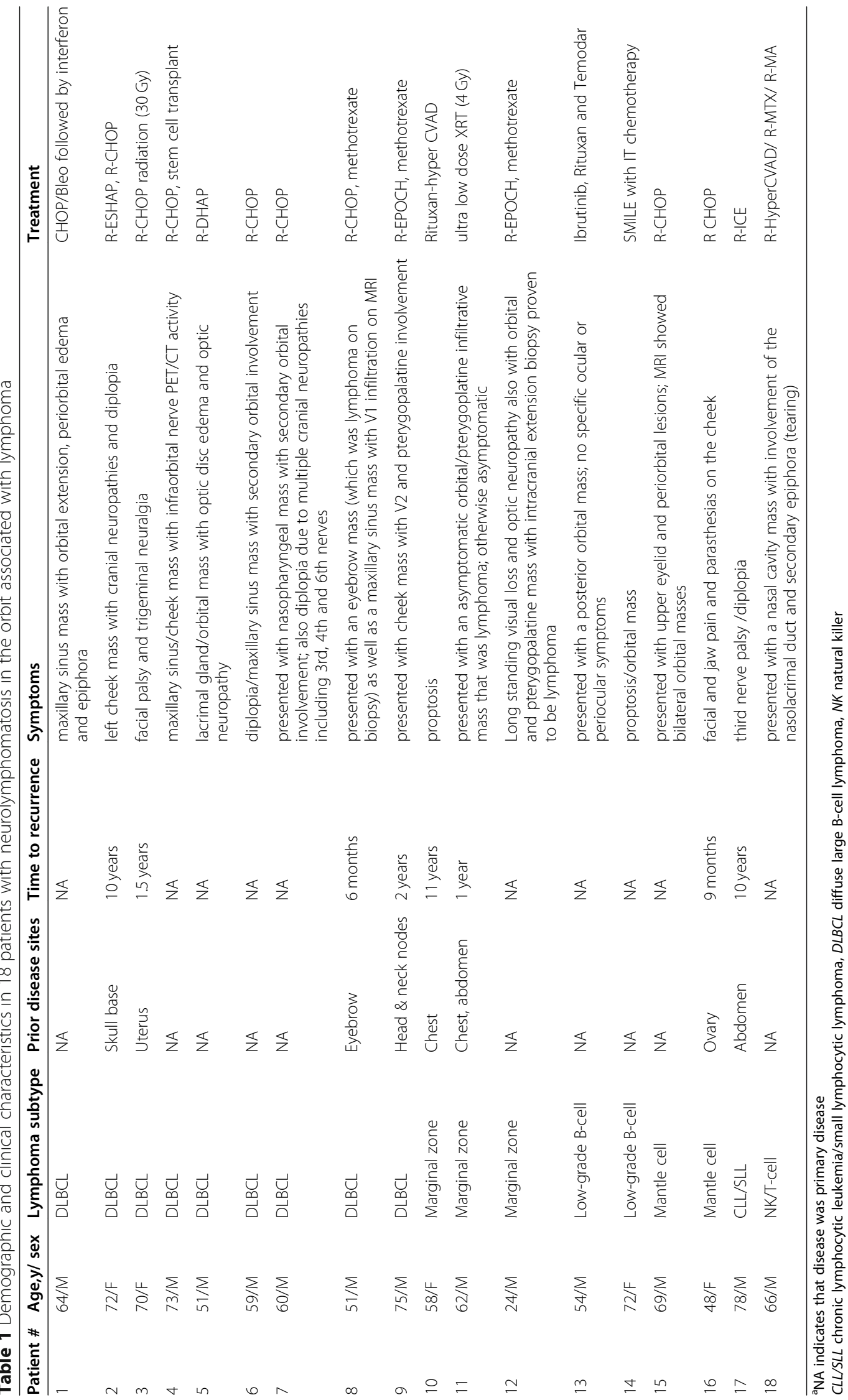




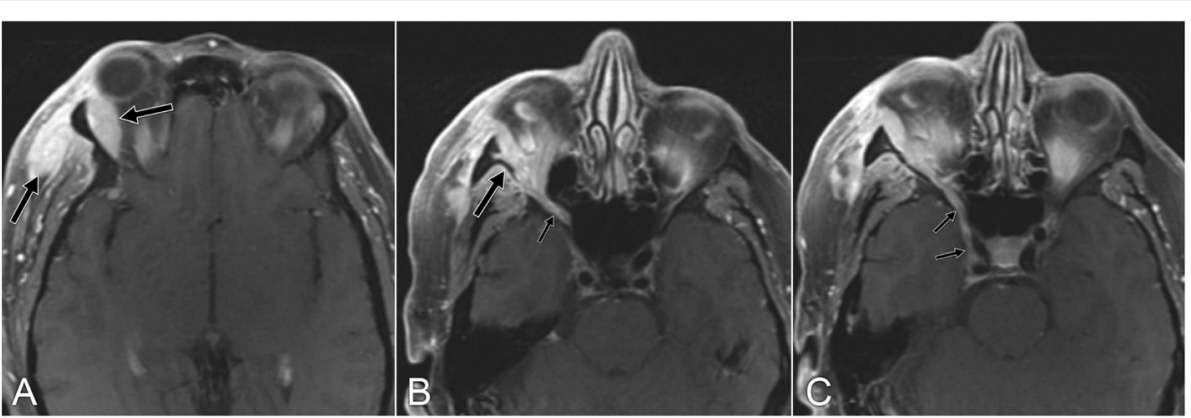

Fig. 1 Axial postcontrast MR images of a 51-year-old-man with DLBCL who presented with diplopia (patient 5). a Mass in the right lacrimal gland and masticator space (arrows). b Extension from the orbital mass (large arrow) through the inferior orbit fissure (small arrow) into the PPF. c Involvement of the foramen rotundum and cavernous sinus (arrows)

was noted between number of sites of neurolymphomatosis and survival $(p=0.26)$.

\section{Discussion}

Our results provide important information about the primary disease sites and patterns of spread of neurolymphomatosis in the orbit and retro-orbital cranial nerves in patients with lymphoma. Neurolymphomatosis most commonly occurred via direct spread from a solid mass in the orbit or maxillofacial region; only a few cases of neurolymphomatosis occurred via direct spread from infiltrative disease in the orbit or hematogenous spread from remote sites. CN V was affected in all cases, and the maxillary division was the division most commonly affected; CN V involvement extended to the PPF and cavernous sinus in the majority of cases. We also

Table 2 Lymphoma type, sites of primary disease, intraorbital disease appearance, and sites of neurolymphomatosis involvement in patients with neurolymphomatosis in the orbit associated with lymphoma

\begin{tabular}{|c|c|c|c|c|}
\hline Patient & Lymphoma type & Site(s) of primary disease & orbital /periorbital disease appearance & Site(s) of NL involvement ${ }^{\mathrm{a}}$ \\
\hline 1 & DLBCL & Maxillary sinus & Spread to $V_{2}$ & $V_{2}, P P F$ \\
\hline 2 & DLBCL & Face & Spread to $V_{2}$ & $V_{2}, P P F$ \\
\hline 3 & DLBCL & Masticator space, neck & Spread to PPF & $V_{2}, V_{3}, P P F, C S, M C$ \\
\hline 4 & DLBCL & Face & Spread to $V_{2}$ & $V_{2}$ \\
\hline \multirow[t]{2}{*}{5} & \multirow[t]{2}{*}{ DLBCL } & Orbital/ & \multirow{2}{*}{$\begin{array}{l}\text { Mass involving lacrimal gland, face, and } \\
\text { lateral orbit }\end{array}$} & \multirow[t]{2}{*}{$V_{2}, P P F, V C$} \\
\hline & & face & & \\
\hline \multirow[t]{2}{*}{6} & \multirow[t]{2}{*}{ DLBCL } & Maxillary sinus/ & \multirow[t]{2}{*}{ Maxillary sinus mass with spread to orbit } & \multirow[t]{2}{*}{$V_{2}, P P F, V C$} \\
\hline & & orbit & & \\
\hline 7 & DLBCL & Orbit, neck, and chest wall & Orbital mass & $V_{2}$, PPF \\
\hline 8 & DLBCL & Forehead/eyebrow & Spread to $V_{1}$ & $V_{1}$ \\
\hline 9 & DLBCL & Face & Spread to $V_{2}$ & $V_{2}, P P F, C S, M C$ \\
\hline 10 & Marginal zone & Orbit & Lacrimal gland and posterior orbital mass & $\|, V_{1}, V_{2}, P P F, C S, M C$ \\
\hline 11 & Marginal zone & Orbit, skull base & $\begin{array}{l}\text { Infiltrative disease involving orbit and } \\
\text { extraocular muscles }\end{array}$ & $I I, V_{1}, V_{2}, P P F, C S, V C, M C$ \\
\hline 12 & Marginal zone & Orbit & mass posterior orbit & $I I, V_{2}, V_{3}, P P F, C S$ \\
\hline 13 & Low-grade B-cell & Masticator space, sphenoid bone, orbit & Masticator mass with spread to orbit & $V_{2}, P P F, C S$ \\
\hline 14 & Low-grade B-cell & Orbit, nasopharynx, neck & Posterior orbital mass & $V_{1}, V_{2}, V_{3}, P P F, C S, V C$ \\
\hline 15 & Mantle cell & Neck and chest & CN involvement & $I I, V_{2}, P P F$ \\
\hline 16 & Mantle cell & Chest node & CN involvement & $V_{2}, V_{3}, P P F, M C$ \\
\hline 17 & CLL/SLL & Abdomen & $\mathrm{CN}$ involvement & $V_{1}, V_{2}, P P F, C S$ \\
\hline 18 & NK/T-cell & Orbit, face, nasal cavity, nasopharynx & $\begin{array}{l}\text { Infiltrative disease involving nasal cavity } \\
\text { and orbit }\end{array}$ & $V_{2}, V_{3}, V I I, P P F, C S, M C$ \\
\hline
\end{tabular}



CLL/SLL chronic lymphocytic leukemia/small lymphocytic lymphoma, CN cranial nerve, CS cavernous sinus, DLBCL diffuse large B-cell lymphoma, $M C$ Meckel's cave, NK ntural killer, PPF pterygopalatine fossa, VC vidian canal 


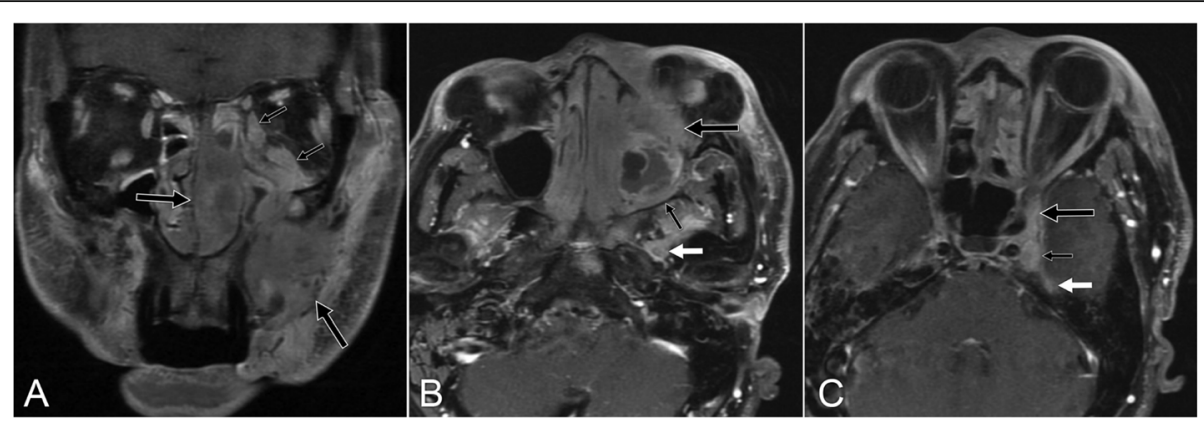

Fig. 2 Postcontrast MR images of a 66-year-old-man with NK/T-cell lymphoma who presented with facial numbness (patient 18). a Coronal image shows a mass in the left side of the face and nasal cavity (large arrows) with infiltration of the orbit including the extra-ocular muscles (small arrows). b Axial image shows the orbital mass (large black arrow) and extension through the inferior orbit fissure to the pterygopalatine fossa (small black arrow). Involvement of the mandibular nerve (V3) is also present (white arrow). c Axial images shows involvement of the cavernous sinus (large black arrow) and Meckel's cave (small black arrow). There is spread via the superficial petrosal nerve (white arrow) to the facial nerve (not shown)

found that while DLBCL is the histologic type of lymphoma most often associated with neurolymphomatosis, it appears to involve fewer sites of neurolymphomatosis than other types of lymphoma and that there is no correlation between number of sites of neurolymphomatosis and survival. The mean interval between the pathologic diagnosis and MRI documentation of the full extent of neurolymphomatosis was 39 days after pathologic diagnosis.

Whereas we found that 13 of 18 patients with neurolymphomatosis in the orbit had a primary tumor in the form of a solid mass in the orbit and/or maxillofacial region, previous reports have stated that lymphoma involving the orbit appears as a well-circumscribed mass in only approximately half of cases and is diffuse in the remaining cases $[9,10]$. Differences between these reports and ours may be related to patient selection: we selected patients who had a pathologic diagnosis of lymphoma and MRI evidence of neurolymphomatosis involving CN II, III, IV, $\mathrm{V}_{1}$, or $\mathrm{V}_{2}$, and this included not only patients with primary tumors that arose in the orbit but also patients with invasion of the orbit from primary tumors in locations such as the sinonasal cavity and masticator space.

Four of the patients in our study had neurolymphomatosis involving $\mathrm{CN}$ II, specifically the optic nerve sheath. Of these 4 patients, 2 had an associated unilateral solid mass in the posterior orbit. Both of the other 2 patients who had neurolymphomatosis involving CN II without a defined mass had bilateral lesions, and 1 had additional infiltrative disease involving the extraocular muscles. Kim et al. [2] noted that 1.3 to $12 \%$ of all lymphomas spread only to the optic nerve. In our study, the patients with $\mathrm{CN}$ II involvement also had spread along $\mathrm{CN}$ V. Other studies have shown that lymphoma may present not only with optic nerve sheath involvement but also with enlargement of the optic nerve [11, 12].

In our study, all 18 cases of neurolymphomatosis involved at least 1 of the 3 divisions of the trigeminal nerve. Lymphomas arising in the premaxillary region may spread to $V_{2}$ via the infraorbital foramen, lymphomas arising in the maxillary sinus may spread to $V_{2}$ via

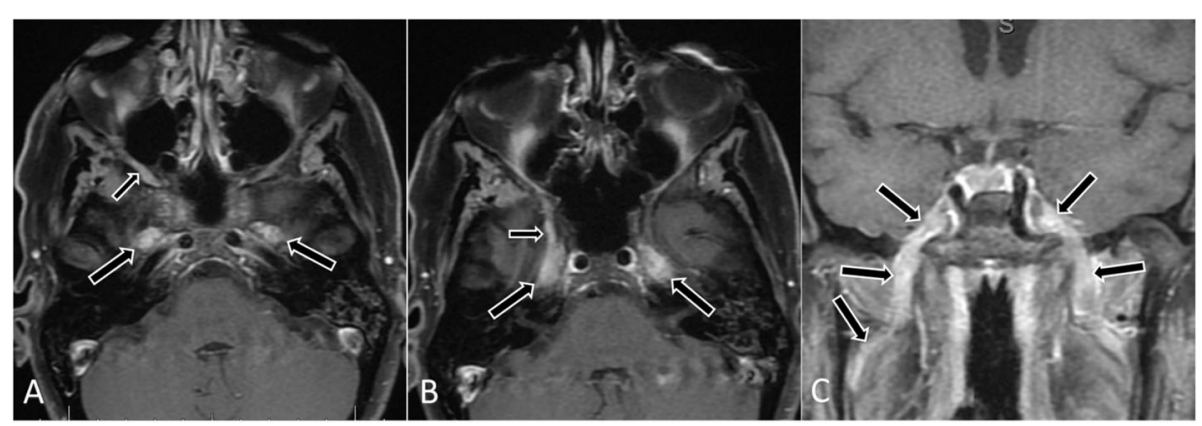

Fig. 3 Postcontrast MR images of a 58-year-old-woman with relapsed Mantle cell lymphoma who presented with facial and jaw pain and parasthesias on the cheek from hematogenous spread (patient 16). a Axial image demonstrates involvement of bilateral mandibular nerves (V3) (large arrows) and the right maxillary nerve (V2) (small arrow). b Axial image demonstrates lymphoma in bilateral Meckle's caves (large arrows) and the right foramen rotundum (V2) (small arrow). c Coronal images demonstrating involvement of bilateral mandibular nerves (V3) (arrows) 
the infraorbital canal and infraorbital nerve, and lymphomas arising in the orbit may spread to $V_{2}$ through the inferior orbital fissure. As the trigeminal nerve is a pathway for disease spread to the ocular adnexa or away from the ocular adnexa to the PPF, foramen rotundum, superior and inferior orbital fissures, cavernous sinus, Meckel's cave, and foramen ovale, these sites are all commonly grouped together as sites likely to be affected by neurolymphomatosis along CN V [2, 13-17]. This direct communication explains the involvement of the PPF and cavernous sinus in our study.

We also found that $\mathrm{CN} \mathrm{V}_{1}$ was involved in only 4 cases while $\mathrm{V}_{2}$ was involved in 17 cases. In our experience, both neurolymphomatosis and PNS from other tumors is more challenging to detect with MRI on $V_{1}$ than on $V_{2}$. This may be related to the fact that $V_{1}$ courses through the superior orbit and is in close proximity to the superior rectus/levator palpebrae complex and may be difficult to visualize on MRI.. Another potential explanation for the more common involvement of $V_{2}$ than of $\mathrm{V}_{1}$ in our study is the finding, demonstrated by multiple authors [18-20], that LMD occurs more commonly in dependent portions of the brain. This possibility could be the topic of further investigation.

In our study, only $1 \mathrm{CN}$ was involved in 13 of the $18 \mathrm{pa}-$ tients (72\%). We found no cases of neurolymphomatosis involving CN I, III, IV, VI, or VIII-XII. Baehring et al. [4] stated that approximately $20 \%$ of patients with neurolymphomatosis will have an isolated cranial neuropathy early in the disease course, often involving CN VII and less frequently involving CN II, IV, or V. With the exception that we found no cases of isolated neurolymphomatosis involving CN IV, which in our experience is also challenging to evaluate on MRI for neurolymphomatosis or LMD, due to its small size and location, our results were in line with what Baehring et al. stated, as only CN II, CN V, and CN VII were involved. In 4 patients there was also spread from the PPF to the vidian canal but not posteriorly to involve the greater petrosal or facial nerves. The involvement of so few cranial nerves may also be related to our selection criteria; we aimed to evaluate neurolymphomatosis in the orbit and periorbital area rather than addressing lymphoma arising in other locations. However, our findings are similar to other reports that diffuse $\mathrm{CN}$ involvement with neurolymphomatosis is not a common presentation $[21,22]$.

CN VII was directly involved in only 1 patient in our study, a patient with NK/T-cell lymphoma who also had involvement of $\mathrm{CN} \mathrm{V}$ with direct spread of neurolymphomatosis via the greater petrosal nerve to the facial nerve. This pattern of $\mathrm{CN}$ spread is similar to the pattern reported by Cruz et al. [23], who found CN VII/VIII involvement in 1 of 6 patients with NK/T-cell lymphoma and $\mathrm{CN} V$ disease in 4 of the 6 patients.
In our study, half of the patients had DLBCL, and DLBCL affected fewer sites with neurolymphomatosis than other lymphoma types did. Given that DLBCL only accounts for only about $10-15 \%$ of all cases of orbital lymphoma according to most series, it was disproportionately associated with the presence of neurolymphomatosis in our series [24]. Similarly, Azevedo et al. [5] reported that involvement of multiple $\mathrm{CNs}$ is rare in cases of DLBCL and Stacy et al. [25] found that 57\% of orbital DLBCL cases were restricted to the ocular adnexa. In contrast, marginal zone lymphoma which accounts for at least $60 \%$ of all cases of orbital lymphoma was seen in only 3 patients with neurolymphomatosis in our series [26]. We found that whereas DLBCL had a localized presentation, marginal zone, mantle cell, and NK/T-cell lymphomas involved a significantly greater number of sites of neurolymphomatosis $(p=0.007)$. In addition, the youngest patient in our study group was 24 years old suggesting that neurolymphomatosis is even rarer in the pediatric population.

In our study, 5 of the 9 patients (56\%) with DLBCL died during follow-up even though DLBCL was associated with significantly fewer sites of neurolymphomatosis. However, no significant correlation was found between the number of sites of neurolymphomatosis and survival. In a multicenter review, Olsen et al. [26] studied disease-specific survival in 797 patients with orbital lymphoma. They found that the histologic subtype was the main predictor of outcome, with DLBCL and mantle cell lymphoma having the lowest 10-year disease-specific survival rates, of 41 and 32\%, respectively.

Limitations of our study include the selection criteria, retrospective nature, and relatively small number of patients. It is known that perineural disease spread can be challenging to detect de novo, and our study could only include disease that had been detected radiologically. For example, patient $3 \#$ had a facial nerve palsy and potentially CN VII disease could not be detected radiographically. However, our study provides more information about neurolymphomatosis, which is a rare manifestation of lymphoma, and may serve as the basis for further investigation.

\section{Conclusions}

Neurolymphomatosis is a rare manifestation of lymphoma that could easily be overlooked by ophthalmologists, oculoplastic surgeons, oncologists, and radiologists caring for patients with lymphoma. Based on our study results, lymphoma with neurolymphomatosis appears to arise as a solid mass in the orbit and/or maxillofacial region or via hematogenous spread to the $\mathrm{CNs}$ and may occur months to years after the original diagnosis of lymphoma. It is most often encountered with DLBCL and is less often seen 
with the typical forms of orbital lymphoma that are low-grade. The most common presentation of neurolymphomatosis in patients with lymphoma appears to be involvement of the trigeminal nerve, specifically the maxillary division including at the infraorbital fissure or foramen rotundum $\left(\mathrm{V}_{2}\right)$, with spread further posteriorly to the PPF and cavernous sinus. Therefore, a systematic search for clinical and radiographic evidence of neurolymphomatosis is imperative for early detection. This may be especially true in patients with DLBCL.

\section{Abbreviations}

CNs: Cranial nerves; DLBCL: Diffuse large B-cell; NHL: Non-Hodgkin lymphoma; NK: Natural killer; PNS: Perineural spread; LMD: Leptomeningeal disease; PPF: Pterygopalatine fossa

\section{Acknowledgements}

We wish to thank Stephanie Deming for editorial assistance with the manuscript.

\section{Authors' contributions}

SJF, BE, and JMD: design of the work, interpretation of data, draft of work. JS: interpretation of data, draft of work. The author(s) read and approved the final manuscript.

\section{Funding}

The University of Texas MD Anderson Cancer Center is supported in part by the National Institutes of Health through Cancer Center Support Grant CA016672.

\section{Availability of data and materials}

All data generated or analysed during this study are included in this published article.

\section{Declarations}

\section{Ethics approval and consent to participate}

The research was HIPAA compliant and adhered to the ethical principles in the Declaration of Helsinki as amended in 2013.

\section{Consent for publication}

Our research contains no personal data.

\section{Competing interests}

We have no financial competing interests to declare.

\section{Author details}

${ }^{1}$ School of Nursing and Health Studies, Georgetown University, Washington, DC, USA. ${ }^{2}$ Orbital Oncology \& Ophthalmic Plastic Surgery, Department of Plastic Surgery, The University of Texas MD Anderson Cancer Center, Houston, TX, USA. ${ }^{3}$ Department of Biostatistics, The University of Texas MD Anderson Cancer Center, Houston, TX, USA. ${ }^{4}$ Department of Neuroradiology, The University of Texas MD Anderson Cancer Center, 1400 Pressler Blvd., Unit 1482, Houston, TX 77030, USA.

Received: 23 March 2021 Accepted: 12 May 2021

Published online: 26 May 2021

\section{References}

1. Bowzyk Al-Naeeb A, Ajithkumar T, Behan S, Hodson DJ. Non-Hodgkin lymphoma. BMJ. 2018;22(362):k3204.

2. Kim JL, Mendoza PR, Rashid A, Hayek B, Grossniklaus HE. Optic nerve lymphoma: report of two cases and review of the literature. Surv Ophthalmol. 2015;60(2):153-65. https://doi.org/10.1016/j.survophthal.2 014.11.004.

3. Grisariu S, Avni B, Batchelor TI, van den Bent MJ, Bokstein F, Schiff D, et al. Neurolymphomatosis: an international primary CNS lymphoma collaborative group report. Blood. 2010;115(24):5005-11. https://doi.org/10.1182/blood-2 009-12-258210.

4. Baehring JM, Damek D, Martin EC, Betensky RA, Hochberg FH. Neurolymphomatosis. Neuro-Oncology. 2003;5(2):104-15. https://doi.org/1 0.1215/15228517-5-2-104.

5. Dantas Azevedo R, Reis F, Torresan Delamain M, de Souza CA. Involvement of cranial nerves in a patient with secondary central nervous system lymphoma. Rev Bras Hematol Hemoter. 2016;38(2):158-60. https://doi.org/1 0.1016/j.bjhh.2016.02.001

6. Diaz-Arrastia R, Younger DS, Hair L, Inghirami G, Hays AP, Knowles DM, et al. Neurolymphomatosis: a clinicopathologic syndrome re-emerges. Neurology. 1992;42(6):1136-41. https://doi.org/10.1212/WNL.42.6.1136.

7. Santos E, Scolding NJ. Neurolymphomatosis mimicking neurosarcoidosis: a case report. J Med Case Rep. 2010;4(1):5. https://doi.org/10.1186/1752-194 7-4-5.

8. Vecchio D, Mittino D, Terazzi E, Nassi L, Conconi A, Monaco F. A case of cranial multinevritis: from the onset to the diagnosis of primary neurolymphomatosis. BMJ Case Rep. 2012;2012.

9. Demirci H, Shields CL, Karatza EC, Shields JA. Orbital lymphoproliferative tumors: analysis of clinical features and systemic involvement in 160 cases. Ophthalmology. 2008;115(9):1626-31. https://doi.org/10.1016/j.ophtha.2008. 02.004 .

10. Valvassori GE, Sabnis SS, Mafee RF, Brown MS, Putterman A. Imaging of orbital lymphoproliferative disorders. Radiol Clin N Am. 1999;371: 135-xi.

11. Behbehani R. Clinical approach to optic neuropathies. Clin Ophthalmol. 2007;1(3):233-46.

12. Kanamalla US. The optic nerve tram-track sign. Radiology. 2003;227(3):718-9. https://doi.org/10.1148/radiol.2273010758.

13. Tomura N, Hirano H, Kato K, Takahashi S, Sashi R, Tate E, et al. Comparison of MR imaging with $C T$ in depiction of tumour extension into the pterygopalatine fossa. Clin Radiol. 1999;54(6):361-6. https://doi.org/10.1053/ crad.1999.0179.

14. Moonis G, Cunnane MB, Emerick K, Curtin H. Patterns of perineural tumor spread in head and neck cancer. Magn Reson Imaging Clin N Am. 2012; 20(3):435-46. https://doi.org/10.1016/.jmric.2012.05.006.

15. Tashi S, Purohit BS, Becker M, Mundada P. The pterygopalatine fossa: imaging anatomy, communications, and pathology revisited. Insights Imaging. 2016;7(4):589-99. https://doi.org/10.1007/s13244-016-0498-1.

16. Liu KC, Hennessey MA, McCall CM, Proia AD. Ocular involvement in neurolymphomatosis. Am J Ophthalmol Case Rep. 2018;10:148-51. https:// doi.org/10.1016/j.ajoc.2018.02.023.

17. Bakst RL, Glastonbury CM, Parvathaneni U, Katabi N, Hu KS, Yom SS. Perineural invasion and perineural tumor spread in head and neck cancer. Int J Radiat Oncol Biol Phys. 2019;103(5):1109-24. https://doi.org/10.1016/j. ijrobp.2018.12.009.

18. Enzmann DR, Rubin JB, DeLaPaz R, Wright A. Cerebrospinal fluid pulsation: benefits and pitfalls in MR imaging. Radiology. 1986;161(3):773-8. https:// doi.org/10.1148/radiology.161.3.3786731.

19. Le Rhun E, Taillibert S, Chamberlain MC. Carcinomatous meningitis: leptomeningeal metastases in solid tumors. Surg Neurol Int. 2013;4(Suppl 4): S265-88. https://doi.org/10.4103/2152-7806.111304.

20. Debnam JM, Mayer RR, Chi TL, Ketonen L, Weinberg JS, Wei W, et al. Most common sites on MRI of intracranial neoplastic leptomeningeal disease. J Clin Neurosci. 2017:45:252-6. https://doi.org/10.1016/j.jocn.201 7.07.020.

21. Kamiya-Matsuoka C, Shroff S, Gildersleeve K, Hormozdi B, Manning JT, Woodman KH. Neurolymphomatosis: a case series of clinical manifestations, treatments, and outcomes. J Neurol Sci. 2014;343(1-2):144-8. https://doi. org/10.1016/j.jns.2014.05.058.

22. Chamberlain MC, Fink J. Neurolymphomatosis: a rare metastatic complication of diffuse large B-cell lymphoma. J Neuro-Oncol. 2009;95(2): 285-8. https://doi.org/10.1007/s11060-009-9918-0.

23. Cruz AA, Valera FC, Carenzi L, Chahud F, Barros GE, Elias J Jr. Orbital and central nervous system extension of nasal natural killer/T-cell lymphoma. Ophthalmic Plast Reconstr Surg. 2014;30(1):20-3. https://doi.org/10.1097/IOP. Ob013e3182a7500e.

24. Sniegowski MC, Roberts D, Bakhoum M, Mc Laughlin P, Yin VT, Turturro F, et al. Ocular adnexal lymphoma: validation of American joint committee on Cancer seventh edition staging guidelines. Br J Ophthalmol. 2014;98(9): 1255-60. https://doi.org/10.1136/bjophthalmol-2013-304847. 
25. Stacy RC, Jakobiec FA, Herwig MC, Schoenfield L, Singh A, Grossniklaus HE. Diffuse large B-cell lymphoma of the orbit: clinicopathologic, immunohistochemical, and prognostic features of 20 cases. Am J Ophthalmol. 2012;154(1):87-98. https://doi.org/10.1016/j.ajo.2012.01.021.

26. Olsen TG, Holm F, Mikkelsen LH, Rasmussen PK, Coupland SE, Esmaeli B, et al. Orbital lymphoma-an international multicenter retrospective study. Am J Ophthalmol. 2019;199:44-57. https://doi.org/10.1016/j.ajo.2018.11.002.

\section{Publisher's Note}

Springer Nature remains neutral with regard to jurisdictional claims in published maps and institutional affiliations.

Ready to submit your research? Choose BMC and benefit from:

- fast, convenient online submission

- thorough peer review by experienced researchers in your field

- rapid publication on acceptance

- support for research data, including large and complex data types

- gold Open Access which fosters wider collaboration and increased citations

- maximum visibility for your research: over $100 \mathrm{M}$ website views per year

At BMC, research is always in progress.

Learn more biomedcentral.com/submissions 